\title{
Adult attachment and incidental memory for emotional words ${ }^{1}$
}

\author{
Jibo $\mathrm{He}^{2}$ \\ Department of Psychology, University of Illinois \\ Nanxin $\mathrm{Li}^{3}$ \\ Department of Psychology, Yale University \\ Tonggui $\mathrm{Li}^{4}$ \\ Department of Psychology, Peking University
}

\begin{abstract}
A dual task of attachment priming and memory recognition was proposed to explore the effect of adult attachment styles on the incidental memory for emotional words. Subjects completed an attachment priming task which intends to activate internal working model of attachment by describing attachment-related scenes, and then an incidental memory recognition test of words which differ in emotional meaning and relevance of attachment styles. Signal detection theory was used to compare the discriminability index and decision criterion of emotional words in subjects of different attachment style. Results showed that subjects with secure attachment styles performed better than insecure-attached subjects in the memory recognition test, in terms of higher hit rate, lower false alarm rate, and higher discriminability index. We extended the influence of attachment styles on cognition to lower level of incidental memory, not just on higher cognitive level with emotional arousal as suggested by previous research.
\end{abstract}

Keywords: adult attachment, incidental memory, internal working model, prime

Attachment is one of most influential theories in social psychology of interpersonal relationships. Bowlby (1973) asserted that attachment is represented in Internal Working Model (IWM), which consists of models of others and model of self. .Working models of other is "his notion of who his attachment figures are, where they may be found, and how they may be expected to respond", whereas working models of self is "his notion of how acceptable or unacceptable he himself is in the eyes of his attachment figures".

IWM of attachment could affect attention to and interpretation of attachmentrelated events (Fuendeling, 1998; Pietromonaco \& Feldman, 2000). IWM could also

\footnotetext{
${ }^{1} \mathrm{~J}$. He and N. Li contributed equally to this work.

${ }^{2}$ Department of Psychology, University of Illinois, Champaign, IL 61820

${ }^{3}$ Department of Psychology, Yale University, New Haven, CT 06511

${ }^{4}$ Correspondence should be addressed to T. Li (Email: litg@pku.edu.cn). Department of Psychology, Peking University, Beijing, 100871, People's Republic of China
} 
enhance the encoding and retrieval of information that is consistent with attachment experience and beliefs. More recently, how attachment style influences memory and cognition is gaining increasingly interest of several researchers.

Hazan and Shaver (1987) first applied the typology of infant attachment to adult romantic relationships by dividing respondents into categories of secure, anxious/ambivalent (preoccupied) and avoidant. Bartholomew (1991) further categorized avoidant attachment into dismissing and fearful, resulting in four types of attachment styles, that is, secure, preoccupied, dismissing and fearful. Besides the categorical approach (Hazan \& Shaver, 1987; Bartholomew, 1991), other researchers proposed a dimensional approach, to study adult attachment (Brennan et al., 1998; Fraley and Waller, 1998). Moreover, some self-report measures have actually been designed in dimensional approach. For example, Brennan et al. (1998) noted that Ainsworth et al's (1978) three attachment styles could be conceptualized by two dimensions of avoidance and anxiety. There are pros and cons of both approaches which we would not go into details in discussing but rather utilize both dimensional and categorical measurements of attachment in the current study.

Previous studies have mainly taken approaches to analyze individual differences in attachment-related memory: memory for laboratory-based events, autobiographical memories, and priming. Studies using these three approaches are reviewed in the following section.

\section{Attachment and memory for laboratory-based events}

The laboratory-based memory approach often uses laboratory-based events as study materials. The advantage of laboratory-based approach is that researchers can flexibly manipulate the to-be-remembered stimuli, such as positive or negative emotion and whether the words are related or unrelated to attachment style. These studies usually measure participants' attachment style by self-report, and focus on the encoding and retrieval of events in memory tasks.

Miller and Noirot (1999) investigated how internal working model of adults influences memory. Participants' attachment styles were measured using Bartholomew \& Horowitz's Relationship Questionnaire. Several weeks later, participants were invited back to the lab for a memory test. All the participants were first asked to write something of either supportive or rejective friendship experience to prime their internal 
working model of attachment. Then, participants read an attachment-related story, which contained equal numbers of positive and negative events distributed systematically across six paragraphs. Their memory for the story was measured using a cued-recall test after they finished reading it. Results showed that adults with secure attachment were associated with better recall of positive events, when participants were primed by rejecting memories before the story. Adults with fearful attachment were associated with better recall of negative story events, when participants were primed by either rejecting or supportive memories. These results support the attachmentschematic information process effect, proposed by Miller and Noirot (1999), who posits that activation of attachment-related experience in memory will prime general attachment beliefs, which will assimilate memory of congruent information.

However, the mechanisms how attachment scheme influences memory are not clear. Do individuals recall attachment-congruent emotional information better than attachment-incongruent information because they paid more attention to congruent information or because they encoded congruent information better? On one hand, secure individuals may have a larger number of inter-connected positive exemplars relative to negative exemplars, for matching and assimilating ongoing attachmentrelated events. Thus, secure attachment style will be positively related to recall of focal events from positive story, and fearful attachment will be positively related to recall of focal events from the negative story. On the other hand, individuals could recall attachment-congruent emotional information better simply because of more attention to congruent information, In this case it will consume more mental source. Thus, secure individuals will recall more positive focal story, less peripheral details, and insecure individuals will recall more negative focal story.

Based on these analyses, Miller and Noirot (1999) examined the possibility of obtaining attachment-schematic processing without the activation of attachment-related memories. Participants provided attachment style ratings and several weeks later read a positive or negative version of a friendship story. There were eight focal episodes in the story and a variety of peripheral details that provided additional information but were not essential aspects of the story. After a filler task, they took a cued recall test about the story, which included 25 focal events and 13 peripheral details. Results found that secure and fearful persons recalled more focal events than peripheral details. Besides, fearful participants recalled more negative focal events, while secure participants had similar memory for positive and negative events. These results supported the role of 
attachment on assimilation processes of memory. Individuals had better memory of attachment-congruent information than attachment-incongruent information.

Fraley et al. (2000) studied the relationship between memory encoding process and attachment style. They examined mechanism of defensive processes in adult with avoidant attachment. They argued that avoidant adults are less attentive to attachment related experience, i.e., defense mechanisms might operate preemptively to limit the amount of information to-be-encoded. An alternative mechanism is that avoidant individuals elaborate less on emotional experience they have encoded. Thus, attachment-related memories would be less accessible, i.e., postemptive suppress or deactivate memories that have already been encoded. To examine the role of preemptive and post-emptive defensive processes, they asked participants to listen a taperecorded 20-minute clinical interview of a woman describing her family relationships, which was constructed to prime attachment-related themes, including intimacy, separation and loss, followed by a cued memory recall test. By statistical analysis of the form of forgetting curves, they found that avoidant adults had poorer recall of emotional experience, which was due to preemptive inhibition of memory encoding. Avoidant adults appeared to be less attentive to emotional events, and encode information less.

\section{Attachment and autobiographical memory}

One limitation of the laboratory-based approach is that events made in laboratory do not reflect participants' personal experience, and may be meaningless to participants. Thus, autobiographical memory approach was proposed to study the relationship of participant's own memory and attachment style. The autobiographical memory approach has several advantages: first, participants recall their own attachmentrelated emotional events, which are meaningful for themselves; secondly, autobiographical memory is a good way to investigate the retrieval process of memory.

A few studies on adults' autobiographical memory focused on the process of memory retrieval. Mikulincer and Orbach (1995) asked participants to recall their own childhood experience, situations, and events in which they had felt a particular emotion, anger, sadness, anxiety, or happiness. Participant's attachment styles were assessed by Hazan and Shaver's measure (Hazan and Shaver, 1987). Results found that secure participants showed relatively moderate retrieval time for negative memories, and they rated these memories of moderate intensity. In contrary, anxious participants had 
shorter retrieval times for negative memories and rated these memories of higher emotional intensity; Avoidant participants had the longer retrieval time for negative memories and the lowest emotional intensity linked to these memories. These results demonstrated that attachment influences the retrieval of memory, and the intensity of associated emotion, which is called attachment-schematic effect.

Similar attachment-schematic effect of memory is also found in several other studies. For example, Mikulincer (1998) examined the relationship of attachment style and autobiographical memory of trust. Participants were asked to recall and describe six well-defined personal experiences, including three positive and three negative episodes, then rated their emotions associated with these experiences, such as, happy, satisfied, hopeful, sad, worried, and angry. Results showed that adults with secure attachment had shorter retrieval time for positive memories, and longer retrieval time for negative memory, relative to insecure adults. In a follow-up study, Mikulincer et al. (2001) used autobiographical memory task to study the influence of attachment styles on the reaction to the needs of others. Participants were asked to recall real-life episodes in which they witnessed another person's plight and their emotional response (e.g., empathy, fear, embarrassment) toward that person. Results found that the higher the attachment anxiety, the faster the retrieval of personal distress memories.

Overall, these studies on autobiographical memory and attachment styles provided consistent evidence that people with secure attachment were quicker to retrieve positive events, whereas insecure attachment (preoccupied or higher anxiety) had faster retrieval of negative events.

\section{Attachment and emotional priming}

Recent research suggested that attachment activation is governed by cognitive rules of schema availability and accessibility. Evidence of the influence of primed attachment styles on inter-personal relationship is beginning to appear in the literature, for example, Mikulincer and Arad (1999) found that primed attachment styles influence cognitive processing.

Only a few studies concerned that primed attachment styles influence individual's memory for emotional events. Rowe and Carnelley (2003) explored cognitive bias resulting from the temporal accessibility of relational schemas. In their study, participants' relational schemas were primed by writing about a relationship of 
either secure, anxious, or avoidant attachment. Afterwards, memory recall of attachment-relevant and attachment-irrelevant words, as well as interpersonal expectations, was measured. Results found that participants primed with a secure-style relational schema recalled more positive attachment words than those primed with an avoidant style. Primed secures showed higher endorsement of positive and lower endorsement of negative interpersonal expectations relative to the other primed style groups. Finally, primed secures reported more positive and less negative affect than the other primed style groups.

\section{Overall view of our study}

The studies reviewed above demonstrated that internal working model of attachment influences the encoding and retrieval of emotional memory, facilitating the cognitive processing of attachment-related information. Nevertheless, the effect of attachment on memory is not conclusive because of the inherent limitations of studies using laboratory materials or autobiographic memory. The stories and scenarios used in the laboratory-based studies were not experienced by subjects, therefore, might be meaningless to the participants; the studies using autobiographic memory can hardly verify the accuracy of the reported memories. Moreover, the attachment schematic effect on emotional memory was found under the condition of conscious and intentional emotion arousal, using arbitrary laboratory materials or unverified personal autobiographical memory. Therefore, it is important to verify the validity of the attachment-schematic effect under conditions without purposeful emotional arousal and more valid memory test. For this purpose, we proposed a dual-task paradigm to study the effect of attachment styles on emotional memory. The primary task was a projective test used to activate subjects' internal working model of attachment. Pictures depicting attachment scenes (for example, a mother waving goodbye to a baby) were shown to subjects. After viewing each picture, subjects would answer some questions relevant to attachment according to their personal experience. The secondary task was an incidental memory task of words flashing by the sides of the pictures. Subjects were not told to memorize the words before the test, but only required to pay attention to all the information on the screen throughout the whole experiment. Based on the studies supporting attachment-schematic effect on emotional memory (Miller, 1999), we expect 
that internal working model primed using attachment-related scenes would improve recognition for attachment-related words than attachment-unrelated words.

\section{Methods}

\section{Subjects}

Fifty-nine undergraduates at Peking University participated in this study in exchange for partial course credit. Subjects were acknowledged their rights and confidentiality before the experiment. All subjects signed the consent form to participate in the experiment. Seventy-five percent of the participants were female. The mean age was 20.8 years $(\mathrm{SD}=1.3)$. All subjects were skilled in typing using the keyboard.

\section{Apparatus}

A PIVcomputer was used to run the experiment program. The monitor was 17 inches with moderate luminance and resolution of $1024 * 768$ pixels. Visual Basic 6.0 is used to program the tasks used in this experiment.

\section{Experiment Design}

The study used $2 * 2 * 2$ mixed designs. The independent variables included between-subject variable attachment style (secure, insecure), and within-subject variables: relevance of words to attachment (related, unrelated) as well as emotional valence of wards (positive, negative). Subjects' attachment styles were measured using the Relationship Questionnaire (Bartholomew \& Horowitz, 1991).

Ninety-six Chinese words were used in the memory recognition task. Words were divided into four equal categories, each containing 24 words: attachment-related positive words (AP words), attachment-related negative words (AN words), attachmentunrelated positive words (UP words), and attachment-unrelated negative words (UN words). The selection of word-pool was rated by professional psychologists and Chinese literature scholars, and received reliable rating score (see Appendix 1). Half of 
the randomly-selected words were shown to the subjects in attachment priming task, the other half were used as foils in the following memory recognition task.

\section{Procedure}

Subjects were first informed about the general purpose of the experiment and confidentiality of their personal information, then signed the consent form to participate in the study. The experiment includes three major parts, an attachment priming task, a word recognition task, and a test of attachment style. The experiment took about 30 minutes.

Attachment priming task. As is shown in Figure 1, in the attachment priming task, subjects were shown a series of eight attachment-relevant pictures in the center of the monitor, and two columns of words flankering at the left and right side of the pictures. The pictures were adapted from Kubos (2000), and intended to activate the internal attachment schemas of subjects. The words flankering by the pictures served as materials for following unexpected memory recognition test. The order of pictures was randomized across the subjects to avoid the confounding of possible sequence effect. After viewing the picture, subjects were told to type in the answers to the following three questions according to their personal experience: (1) what scene does this picture depict? (2) How the people feel right now in the picture? (3) Under such circumstance, what would the people do later on?

During the process of the attachment priming task, two columns of words flashed by the left and right sides of the pictures. The first word appeared three seconds following the onset of the picture in one of the six possible places (three for either box) (Figure 1). For each picture, six words were shown for 5 times, appearing one second at a time. The choice of the words from the 96-word-pool and the appearance place of the words were randomized.

Memory recognition task. Immediately after the attachment priming task, subjects proceeded to the memory recognition test. Subjects were not informed about the memory test, and were not told to direct attention to the words during the priming task. Forty-eight words shown in the priming task, combined with forty-eight foils, were used in the memory recognition task. For all the ninety-six words, subjects were asked to judge whether the words had appeared in the priming task. The sequence of the words was randomized. 


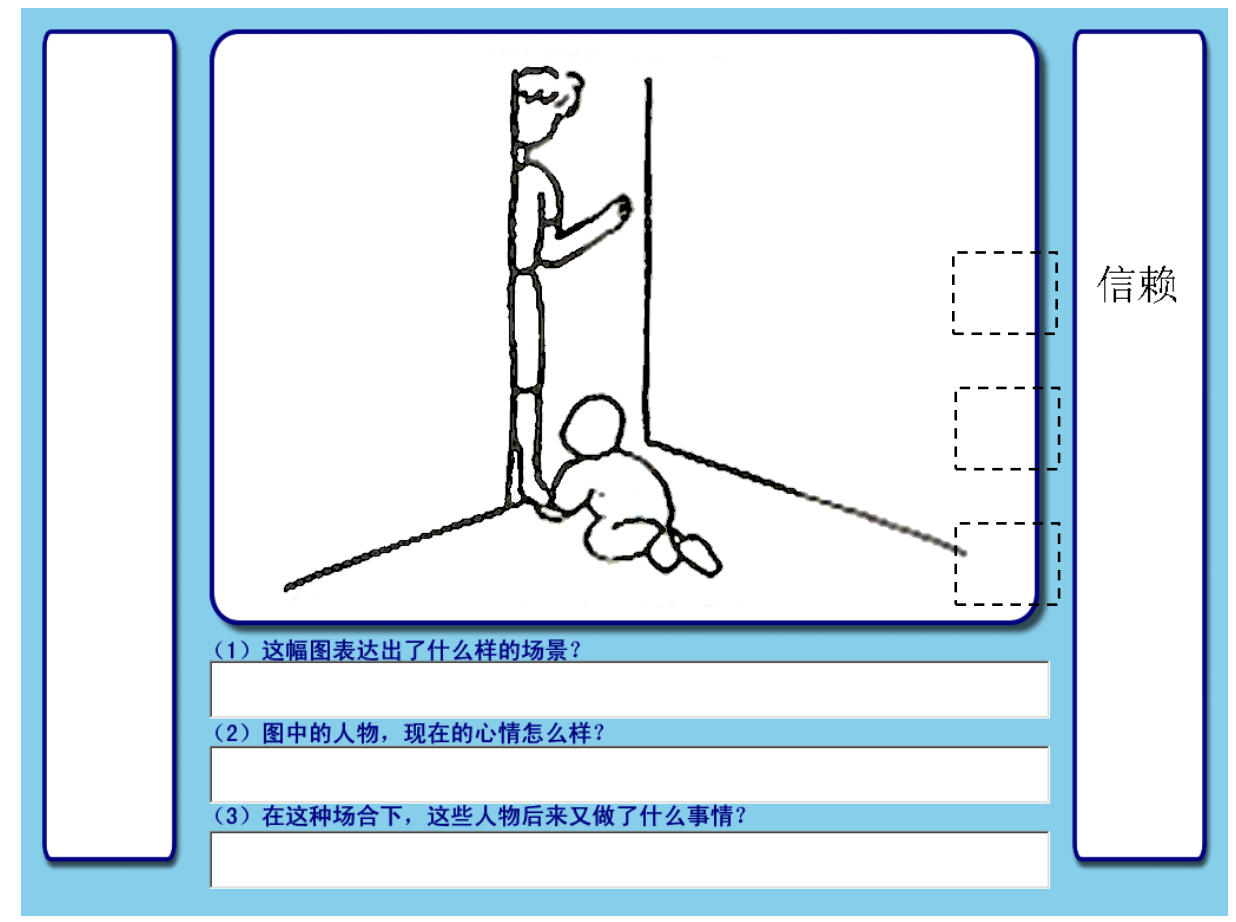

Figure 1. Window of the main task. The large picture in the middle was one of the eight pictures, showing mother waving goodbye to baby. Six dotted-line boxes showed the possible place for word's appearance in the 2 columns beside the picture.

The Chinese characters in the up-right box mean 'trust' in the category of AP words. Below the picture were 3 questions subjects had to type answers in corresponding box.

Measurement of attachment style. Following the memory recognition test, we assessed subjects' attachment style with a Chinese version of the Relationship Questionnaire (Bartholomew \& Horowitz, 1991).

\section{Data Analysis}

Signal detection theory, which states that memory recognition decisions are based on the signal strength relative to a decision criterion, has been the dominant theoretical framework to study memory recognition task (Wixted, 2007). Therefore, the data were analyzed in the framework of signal detection theory. Hit rate and false alarm rate were used to describe memory performance. Because accuracy of performance measured by hit rate and false alarm rate might confound with decision criterion, criterion (C) and discriminability index (d') were also computed to compare discriminability and decision criterion of subjects of different attachment style. 


\section{Results}

The RQ questionnaire was used to measure the attachment styles of subjects. Thirteen-nine subjects reported as secure attachment (66.1 percent of total subjects); twenty subjects were insecure attachment, making 33.9 percent of the total subjects. Among the insecure attached subjects, 6 were dismissing (10.2 percent), 7 were preoccupied, and another 7 were fearful attachment (each making 11.9 percent of all subjects).

Signal detection theory (SDT) was used to measure the sensitivity and accuracy of subjects with different attachment styles to distinguish words in memory from foils. For the 96 words in the recognition test, half of them which had appeared during the attachment priming task were signal; the other half which did not appear in attachment priming task, but used as foils in memory recognition task, were noise. SDT proposes several important indices to measure the accuracy of memory, including hit rate, false alarm rate, sensitivity, and decision criterion. The acceptance of a formerly-displayed word is called as a 'hit'; on the contrary, the acceptance of words which had never been is a 'false alarm'. We would analyze the 'hit' rate and 'false-alarm' rate separately.

\section{Hit rate}

Hit rate is computed as the number of correct acceptance of a signal over the total number of signals. The average hit rate of all subjects is $.540(S D=.147)$, implying the difficulty of the recognition task is moderate. Hit rates of each experiment conditions are summarized in Table 1. A $2 * 2 * 2$ repeated-measure analysis of variance was carried out to compare the hit rate of memory test with attachment style (secure or insecure), word theme (attachment-related or attachment-unrelated words), and word valence (positive or negative words) as factors. 
Table 1. Hit rate of words by different attachment styles

\begin{tabular}{lllllllll}
\hline & \multicolumn{4}{l}{ Attachment-related words } & \multicolumn{3}{l}{ Attachment-unrelated words } \\
\cline { 2 - 9 } Attachment style & \multicolumn{2}{l}{ Positive word } & \multicolumn{2}{l}{ Negative word } & \multicolumn{2}{l}{ Positive word } & \multicolumn{2}{c}{ Negative word } \\
\cline { 2 - 9 } & $M$ & $S D$ & $M$ & $S D$ & $M$ & $S D$ & $M$ & $S D$ \\
\hline Secure (n=39) & 0.64 & 0.18 & 0.62 & 0.21 & 0.50 & 0.20 & 0.54 & 0.25 \\
insecure (n=20) & 0.60 & 0.21 & 0.60 & 0.21 & 0.38 & 0.18 & 0.31 & 0.19 \\
\hline
\end{tabular}

Results show a significant interaction effect between word theme and attachment style, $F_{(1,57)}=6.38, p<.05$, but no other two-way or three-way interactions were significant, all $p \mathrm{~s}>.05$. The results also showed that hit rate for attachment-related words $(M=0.614, S D=0.023)$ was significantly better than attachment-unrelated words $(M=0.434, S D=0.025), F_{(1,55)}=39.77, p<.01$, which confirmed that the activation of attachment styles facilitated information processing of attachment-related words. Moreover, those secure attachment participants got higher hit rate $(M=0.575, S D$ $=0.022)$ than insecure ones $(M=0.472, S D=0.031), F_{(1,57)}=7.25, p<.01$. However, there is no difference for the hit rate for positive words $(M=0.532, S D=0.022)$ and negative words $(M=0.515, S D=0.023), F_{(1,55)}=0.60, p>.05$.

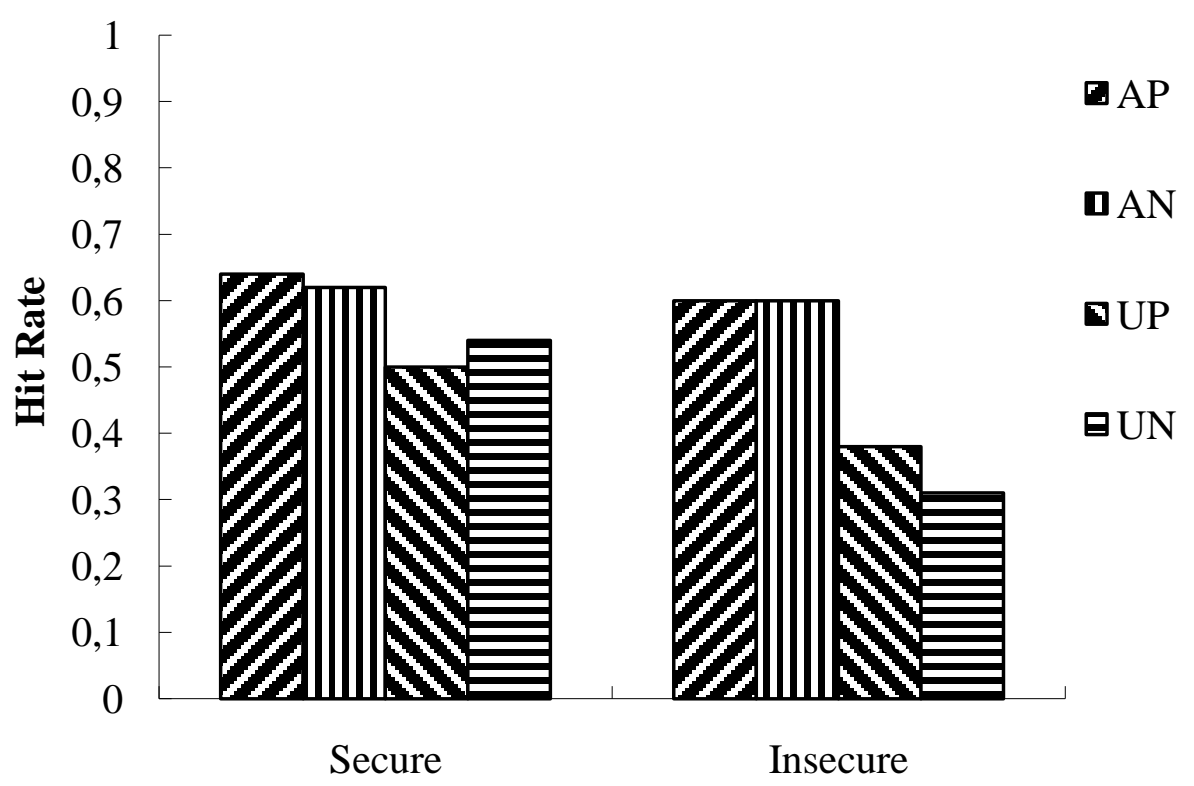

Attachment Styles

Figure 2. Hit rate for subjects by different attachment styles.

(Note: AP: attachment-related positive; AN: attachment-related negative; UP: attachment-unrelated positive; UN: attachment-unrelated negative) 


\section{False-alarm rate}

The false-alarm rate was computed as the frequency of acceptance of noise over the total number of noises. The average false alarm rate of all subjects was 296 (SD $=.125$ ). Table 2 presents the means and standard deviation of false alarm rate. ANOVA analysis showed significant effects for attachment styles, $F_{(1,57)}=5.91, p<.05$. and word theme $F_{(1,55)}=94.95, p<.01$, but the main effect of word valence (positive or negative) was not significant, $F_{(1,55)}=1.51, p>.05$. Similar to the results of hit rate, only the interaction effect between word theme and attachment style was significant, $F_{(1,57)}=$ $4.39, p<.05$, all other two-way or three-way interactions were not significant, all ps $>.05$. False alarm for attachment-related words $(M=0.414, S D=0.023)$ was significantly higher than attachment-unrelated ones $(M=0.203, S D=0.016)$. Besides, false alarm rate for secure subjects $(M=0.269, S D=0.019)$ was lower than insecure subjects $(M=0.349$, $S D=0.027)$. However, there was no significant difference between positive words $(M$ $=0.297, S D=0.020)$ and negative ones $(M=0.321, S D=0.018)$.

Table 2. False alarm rate of words by different attachment styles

\begin{tabular}{llllllllll}
\hline & \multicolumn{3}{l}{ Attachment-related words } & \multicolumn{4}{l}{ Attachment-unrelated words } \\
\cline { 2 - 8 } Attachment style & \multicolumn{3}{l}{ Positive word } & \multicolumn{2}{l}{ Negative word } & \multicolumn{3}{l}{ Positive word } & \multicolumn{2}{l}{ Negative word } \\
\cline { 2 - 9 } & M & SD & M & SD & M & SD & M & SD \\
\hline Secure (n=39) & 0.37 & 0.19 & 0.33 & 0.18 & 0.17 & 0.12 & 0.20 & 0.14 \\
insecure (n=20) & 0.46 & 0.24 & 0.49 & 0.20 & 0.19 & 0.18 & 0.25 & 0.14 \\
\hline
\end{tabular}




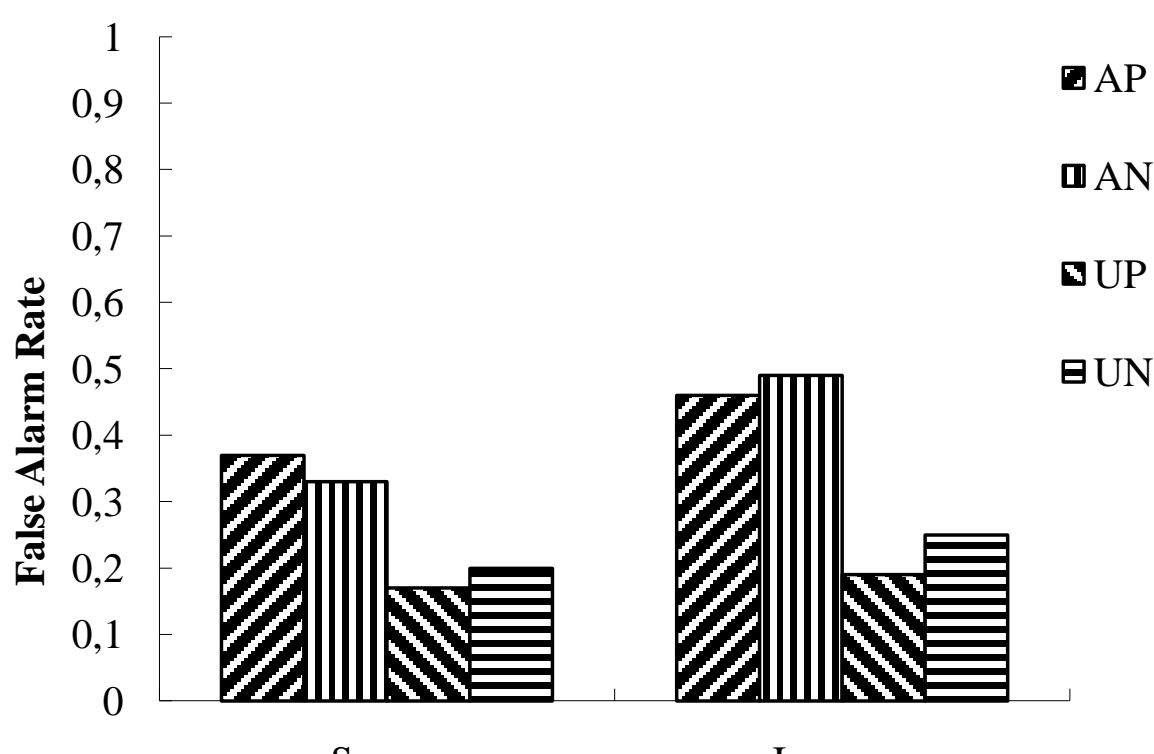

Secure

Insecure

Attachment Styles

Figure3. False-Alarm rate by difference attachment styles

(Note: AP: attachment-related positive; AN: attachment-related negative; UP: attachment-unrelated positive; UN: attachment-unrelated negative). Criterion (C) and discriminability index (d')

The measurements of hit rate and false alarm rate discussed above are helpful indices of how accurately people performed in memory recognition test. However, hit rate and false alarm rate depend on the judgment criterion of subjects, therefore cannot accurately reflect subjects' ability distinguish signal from noise. We derived criterion (C) and discriminability index (d') from hit rate and false alarm rate to investigate subjects' response bias and discriminability of words independently. The primary benefit of d' is that its value does not depend upon the criterion, or the response bias, the subjects adopted, therefore is a reliable measure of how they can discriminate or memorize the displayed words. 


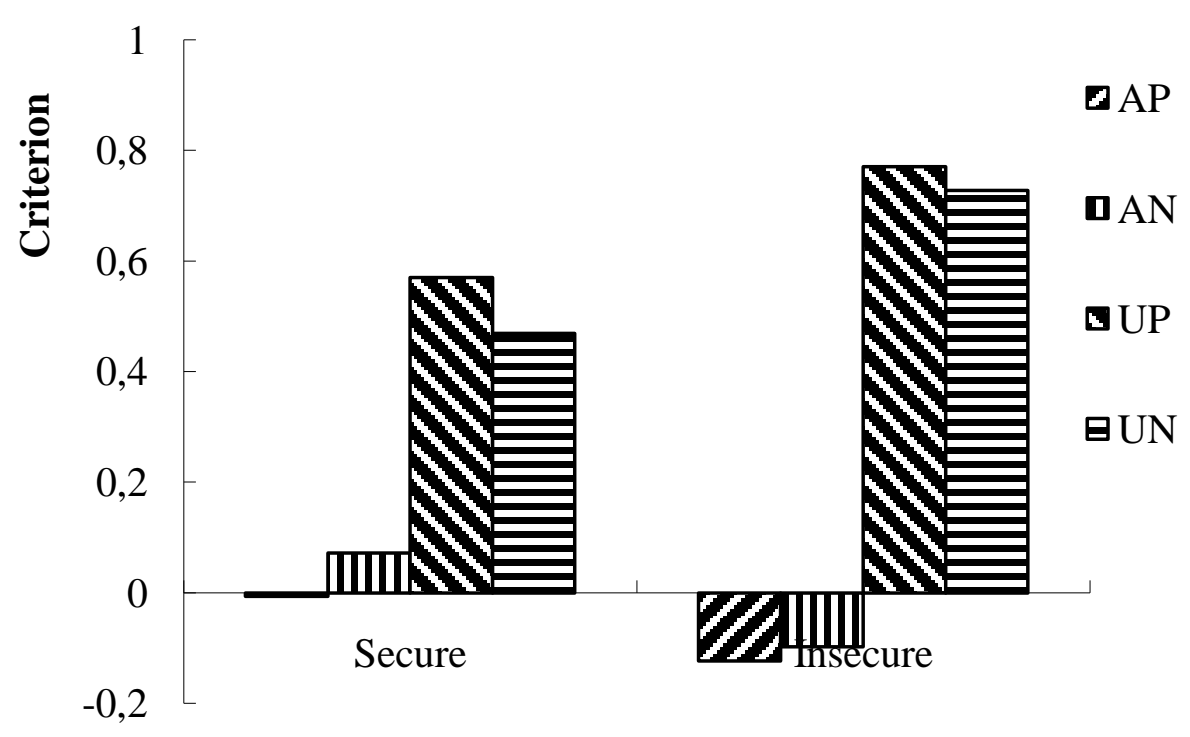

Attachment Styles

Figure 4. Response criterion

(Note: AP: attachment-related positive; AN: attachment-related negative; UP: attachment-unrelated positive; UN: attachment-unrelated negative)

A three-way repeated measure ANOVA with attachment style, word theme, and word valence as independent measures is used to compare the response criterion of subjects. The results showed a significant main effect of word theme, $F_{(1,57)}=88.296, p$ $<.001$. Subjects responded to attachment-unrelated words $(M=.039)$ more conservatively than attachment-related words $(M=0.635)$. Interaction effect of word theme and attachment style is also found to be significant, $F_{(1,57)}=6.744, p<.05$. No main effect of attachment styles is found, $F_{(1,57)}=.137, p>.10$, suggesting that the subjects holding similar response criterion. No main effect of word valence, other twoway interaction effect are found, $p>.10$. 


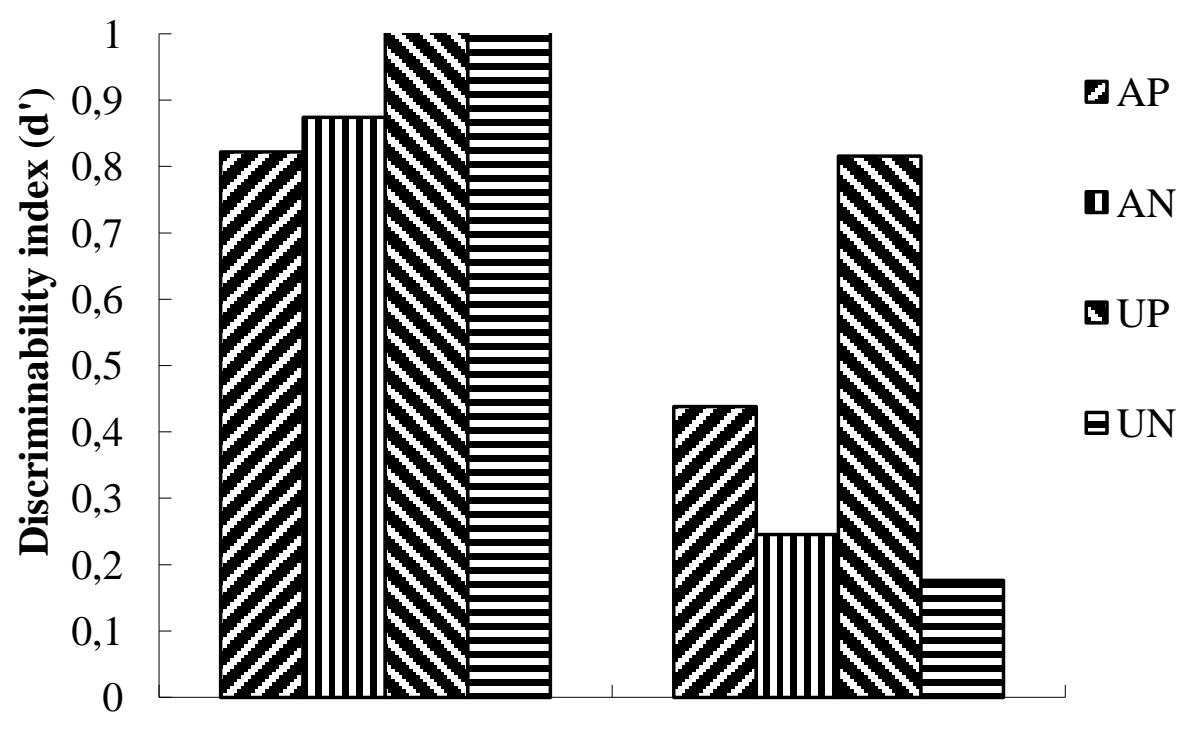

Secure

Insecure

Attachment Styles

Figure 5. Discriminability index (d')

(Note: AP: attachment-related positive; AN: attachment-related negative; UP: attachment-unrelated positive; UN: attachment-unrelated negative)

Discriminability index (d') was used to compare memory performance under each experiment conditions with three-way repeated measure ANOVA. Results show a significant interaction effect of attachment style and word valence, $F_{(1,57)}=2.424, p$ $<.01$ (See Figure 4.). We also find significant main effect of attachment style, $F_{(1,57)}$ $=22.723, p<.001$. Securely attached subjects $(M=0.986)$ performed better than the insecures $(M=0.419)$. Main effect of word valence is also significant, $F_{(1,57)}=2.161, p$ $<.05$, which is because subjects with insecure attachment performed better for positive words $(M=0.627)$ than negative words $(M=0.211)$.

\section{Discussion}

To sum up, subjects with secure attachment styles performed better than the insecure attached subjects in the memory recognition test, in measures of higher hit rate, lower false alarm rate, and higher discriminability (d'). Subjects also had poorer memory for attachment-related words than attachment-unrelated words, with lower discriminability of attachment related words than unrelated words. The memory performance of either emotionally positive or negative words does not differ 
significantly. However, notably, subjects with insecure attachment tended to perform better for positive words than negative words.

The findings with word theme supported the "attachment-schematic information process effect" (Miller, 1999). When engaging in the attachment priming task (view attachment related scenes, and answer attachment related questions), subjects' internal working model for attachment is activated. IWM, built based on attachment-related experience in memory, is a general attachment belief about self and others, and can facilitate processing of attachment related information. Therefore, subjects will be more sensitive to attachment related words shown in the memory recognition task, resulting higher hit rate; and also because of the relevance of the never shown attachment related words to the activated IWM, subjects tend to misjudge them as target, resulting higher false alarm rate.

Another important finding is that subjects with secure attachment styles performed better than insecure attachment in the memory recognition task. This result is congruent with previous finding that children with secure attachment have advantages in encoding and retrieving emotional events over children with insecure attachment (Farrar, Fasig, \& Welch-Ross, 1997). People tend to pay more attention to emotional information that fits into their attachment scheme, and information that is incongruent with their attachment scheme is ignored or suppressed. People with secure attachment has a better treatment of both positive and negative information, therefore, process positive and negative words better than insecure attachment. On the contrary, subjects with insecure attachment are more sensitive to negative information, which can gain support from our finding that subjects with insecure attachment cannot discriminate negative words from foils as well as positive ones.

Notably, in this study, subjects with secure attachment had similar memory of positive and negative words. This is not consistent with previous studies, which suggested that secure attached people tend to report positive events or memory. Belsky (1996) found that children (3 years old) with secure attachment reported more positive emotional events in a delayed memory recognition test of emotional events. Miller and Noirot (1999) also found people with secure attachment had better memory for positive events in a reasoning task. The null finding on memory advantage of positive words may be a result of the fact that little attention was paid to the words during attachment priming task. The subjects may not be emotionally aroused, and have little time to process the emotional meaning of the words. The studies that found better memory for 
attachment-congruent information usually required deep cognitive processing of emotional events (Belsky, 1996; Miller \& Noirot, 1999).

Our study extended the influence of attachment on memory and cognition. Previous research, using methods like experimental manipulated emotional events, autobiographical memory of emotional events, or emotional priming, all required the subjects to process emotional events consciously, and with a significant level of emotional arousal. We would expect attachment influence the memory performance in these higher level cognitions, in which internal working model can act as a scheme to facilitate attachment related information. Notably in this experiment, even if subjects did not intentionally process the information, we still found better memory performance for attachment related information. In conclusion, internal working memory of attachment influences and facilitates attachment related information, not only at a higher cognition level with intense emotional arousal, but also at a lower cognition level of incidental memory.

Our findings provide further support for the attachment-schematic effect on emotional memory. However, it is important to consider several limitations when interpreting and generalizing our findings. In this study, we recruited fifty-nine participants from a convenient sample of undergraduate students in our college. The sample size is relatively small and homogeneous in their academic background. Although our findings bear a robust statistical power, it is important to verify this study using larger and more diversified sample.

\section{References}

Ainsworth, M. D. S., Blehar, M.C., Waters, E., \& Wall, S. (1978).Patterns of Attachment: A Psychological Study of Strange Situation. NJ: Erlbaum, Hillsdale. Alexander, K., Goodman, G., Schaaf, J., Edelstein, R., Quas, J., \& Shaver, P. (2002). The role of attachment and cognitive inhibition in children's memory and suggestibility for a stressful event. Journal of Experimental Child Psychology, 83: 262-290.

Baldwin, M. (1992). Relational schemas and the processing of social information. Psychological Bulletin,112: 461-484.

Baldwin, M., Keelan, J., Fehr, B., Enns, V., \& Koh-Rangarajoo, M. (1996). Socialcognitive conceptualization of attachment working models: Availability and 
accessibility effects. Journal of Personality and Social Psychology, 71: 94-109.

Bartholomew, K., \& Horowitz, L. M. (1991). Attachment styles among young adults: A test of a four-category model. Journal of Personality and Social Psychology, 61: 226-244.

Belsky, J., Sprita, B., \& Crnic, K. (1996). Infant attachment security \& affectivecognitive information processing at age 3. Psychological Science, 7: 111-114.

Bowlby, J. (1997)[1969]. Attachment and loss. Vol. 1. Attachment. Pimlico.

Bowlby, J. (1997)[1973]. Attachment and loss. Vol. 2. Separation. Pimlico.

Brennan, K. A., Clark, C. L., Shaver, P. R. (1998). Self-report measurement of adult attachment: an integrative overview. In J.A. Simpson \& W. S. Rholes (Eds.). Attachment Theory and Close Relationships. (pp.46-76). New York: The Guilford Press.

Collins, N. L., Read, S. J.(1994). Cognitive representations of attachment: The structure and function of working models. Advances in Personal Relationships, 5, 53-90.

Crittenden, P. M., Lang, C. , Claussen, A. H., Partridge, M. F. (2000).Relations among mothers' dispositional representations of parenting. In Crittenden P C. \& Claussen A H. (Eds.), The Organization of Attachment Relationships: Maturation, Culture, and Context. (pp.214-233). Cambridge University Press. Farrar, M. J. , Fasig, L. G. (1997). Attachment and emotion in autobiographical memory development. Journal of Experimental Child Psychology, 67, 389-408.

Fraley, R. C., Garner, J. P., Shaver, P. R.(2000). Adult attachment and the defensive regulation of attention and memory: Examining the role of preemptive and postemptive defensive processes. Journal of Personality and Social Psychology, 2000, 79: 816-826.

Fraley, R. C., Waller, N. G. (1998). Adult attachment patterns: A test of the typological model. In Simpson, J. A. \& Rholes, W.S. (Eds), Attachment Theory and Close Relationships. (pp.77-114). The Guilford Press.

Fuendeling, J. M. (1998). Affect regulations as a stylistic process within adult attachment. Journal of Social and Personal Relationships.15 (3): 291-322.

Griffin, D., \& Bartholomew, K. (1994). Metaphysics of measurement: The case of adult attachment. In K. Bartholomew \& D. Perlman (Eds.), Advances in personal relationships, Vol. 5: Attachment processes in adulthood (pp.17-52). London: Jessica Kingsley.

Hazan, C., \& Shaver, P. (1987). Conceptualizing romantic love as an attachment 
process. Journal of Personality and Social Psychology, 52: 511-524.

Hazan, C., \& Zeifman, D. (1994). Sex and the psychological tether. In K. Bartholomew \& D. Parlman (Eds.), Advance in personal relationship, Vol. 5: Attachment process in adulthood. (pp. 151-178). London: Jessica Kingsley Publishers Ltd.

Kirsh, S. J., \& Cassidy, J. (1997). Preschoolers' attention to and memory for attachment relevant information. Child Development, 68: 1143-1153.

Kobak, R., \& Sceery, A. (1988). Attachment in late adolescence: Working models, affect regulation, and perception of self and others. Child Development, 59: 135-146.

Kubo, M. (2000). Attachment representation and a projective test with pictures of parent-child interaction (in Japanese). The Japanese Journal of Psychology, 70 (6): 477-484.

Main, M. (1999). Attachment theory: eighteen points with suggestions for future studies. In Cassidy, J. and Shaver, P.R. (Eds), Handbook of Attachment. (pp. 845-888). New York: Guilford Press

Main, M., Kaplan, N., \& Cassidy, J. (1985). Security in infancy, childhood, and adulthood: A move to the level of representation. In I. Bretherton, E. Waters (Eds.), Growing Points in Attachment Theory and Research. (pp. 66-104). Monographs of the Society for Research in Child Development .

Mikulincer, M. (1998). Adult attachment style and individual differences in functional versus dysfunctional experiences of anger. Journal of Personality and Social Psychology, 74: 513-524.

Mikulincer, M., \& Arad, D. (1999). Attachment working models and cognitive openness in close relationships: A test of chronic and temporary accessibility effects. Journal of Personality and Social Psychology, 77: 710-725.

Mikulincer, M., Gillath, O., Halevy, V., Avihou, N., Avidan, S., \& Eshkoli, N. (2001). Attachment theory and reactions to others' needs: Evidence that activation of the sense of attachment security promotes empathic responses Journal of Personality and Social Psychology, 81: 1205-1224.

Mikulincer, M., \& Orbach, I. (1995). Attachment styles and repressive defensiveness: The accessibility and architecture of affective memories. Journal of Personality and Social Psychology, 68: 917-925.

Miller, J. B. (1999). Attachment style and memory for attachment-related events. Journal of Social and Personal Relationships, 16: 773-801.

Miller, J. B., \& Noirot, M.(1999). Attachment memories, models and information 
processing. Journal of Social and Personal Relationships, 16, 147-173.

Philippot, P., \& Schaefer, A.(2001). Emotion and memory. In T.J., Mayne \& G.A. Bonanno (Eds.) Emotions: Current Issues and Future Directions. (pp:82-122). The Guilford press.

Pietromonaco, P. R., \& Barrett, F. L.(2000). The internal working models concept: what do we really know about the self in relation to others? Review of General Psychology, 4: 155-175.

Quas, J., Goodman, G., Bidrose, S., Pipe, M., \& Craw, S. (1999). Emotion and memory: children's long-term remembering, forgetting, and suggestibility. Journal of Experimental Child Psychology, 72, 235-270.

Rowe, A., \& Carnelley, K. B. (2003).Attachment style differences in the processing of attachment-relevant information: Primed-style effects on recall, interpersonal expectations, and affect. Personal Relationships, 10: 59-75.

Sroufe, L. A., \& Waters, E. (1977). Attachment as an organizational construct. Child Development, 48: 1184-1199.

Waters, E., \& Deane, K. (1985). Defining and assessing individual differences in attachment relationships: Q-methodology and the organization of behavior in infancy and early childhood. In Bretherton, I. \& Waters, E. (Eds.), Monographs of the Society for Research in Child Development, 50, 41-65.

Wixted, J.T. (2007). Dual-process theory and signal-detection theory of recognition memory. Psychological Review, 114:152-176. 